\title{
Four groups join battle
}

\section{Washington}

THE US Patent Office is now wrestling with competing claims to patents on hightemperature superconductivity from four different research groups - at IBM, AT\&T, the University of Houston and the US Navy. The patent office says there is a conflict over priority in the four claims to have discovered useable versions of the copper oxide superconductors. If the patents office can resolve the conflict, its decision could be a boon for the organization whose claim succeeds.

The conflict, legally called an interference' proceeding, has arisen because the patent applications by the four are similar, overlapping, and were filed at almost the same time. The parties to the dispute have each filed a string of patent applications for both the lanthanum copper oxide materials discovered in 1986 by Nobel prizewinners Georg Bednorz and Alex Müller, of IBM Zurich, and the yttriumbased copper oxides discovered by Paul Chu of the University of Houston and Maw-Kuen Wu of Alabama University in January 1987. It is widely believed that the yttrium compounds will have more general commercial application than the lanthanum materials.

The US Patent Office will have to decide not only whether patent applications for the lanthanum oxide superconductors can be extended to cover the yttrium compounds, but also whether applications based on mixed-phase materials of unknown crystal structure are valid (as in the case of Chu's first patent application for yttrium copper oxide material).

Information about patent applications for the superconductor materials began to come to light last summer, in Europe and Japan, where by law applications are made public 18 months after submission (or after the earliest priority date claimed). US patents are not published until granted, but several of the European and Japanese patent applications include priority claims for US patents and so disclose US filing dates.

The application from the US Naval Research Laboratory has not previously been known of, having been filed only in the United States. At the applications stage, even cases of interference are not publicized by the US patent office, but Cynthia Stevens, an IBM spokeswoman on patents, confirms the identity of the four competing applicants.

Japanese patent applications are notable by their absence in the dispute, in contrast with the common fear in the United States that Japan will be the first to exploit the commercial applications of the high-temperature superconductors. One explanation may be that the early patent applications by University of Tokyo researchers are narrowly drawn and cover only the lanthanum oxides (see Nature 335, 389; 29 September 1988).

Japan's Ministry of International Trade and Industry (MITI), which has filed broad applications worldwide covering the yttrium oxides, may claim interference at a later stage, according to Christopher Vear of the British Technology Group who is monitoring patent applications for the new materials. But MITI filed after the US groups in January 1987 and does not seem to have a strong position.

Japan's real strength lies in patent applications for devices made from the new materials and processes for making the superconductors into wires and thin films. Japanese companies, in particular Sumitomo Electric Corporation, have filed hundreds of such applications in Japan and many have been combined into broad patent applications in Europe, where Japanese interests have filed most applications. According to Vear's latest figures, Japan has filed 80 applications in Europe compared with 28 for the United States, 5 for West Germany , 4 for Britain, 3 for France and 1 each for the Soviet Union and Hungary.

The only patent so far granted has been awarded by the US Patent Office to John B. Vander Sande and Gregory J. Yurek at the Masssachusetts Institute of Technology (MIT) for a process that combines the new ceramic materials with silver to make a more malleable material (see Nature 336, 607; 15 December 1988). But soon after the award was announced, Sumitomo filed a claim for interference with a similar patent application it had filed within a day of the MIT researchers, according to Vear. Such claims of interference can be expected to multiply dramatically in the near future.

Patent interference cases in the United States can take years to resolve. One example is the battle over patent applications for the gas discharge laser, which took 28 years. The dispute over patent rights on high-temperature superconductor materials may become such a case because of the large number of parties involved. But a long legal battle could work to the eventual winner's advantage. If, as many experts predict, commercial applications of the new materials will not be feasible for at least a decade and because, in the United States, the life of a patent begins only after it is issued, the group to which the patent is eventually granted may enjoy licence fees for longer than if its claim had never been challenged.

David Swinbanks

- On page 49 of this issue, the recently developed 'electron' superconductors show behaviour similar to the more established 'hole' superconductors.

\section{London}

THE Union of Scientists and Inventors' Societies of the USSR has established a special "international commission for relations with former compatriots", aimed at establishing links with Soviet scientists and engineers now working in the West. Such people have hitherto been regarded as ungrateful renegades, who have accepted the benefits of a Soviet education and then decamped to the capitalists. The new commission, however, considers them a potential channel for establishing closer cooperation between Soviet science and the West. Interviewed by Sotsialisticheskaya Industriya, commission member Academician Yurii Gulyaev suggested a whole range of ways in which the émigrés could help Soviet science, from taking Soviet graduate students into their laboratories for a year or two to organizing joint research groups. Many countries, Gulyaev said, gained considerably by working with their émigré scientists in this way - Hungary especially. "We have been accustomed to working only through official channels" . . . but personal contacts and informal links are sometimes more effective." $V . R$.

\section{Three per cent is six}

\section{London}

BRITISH universities will receive a 3 per cent increase in government grants for recurrent expenditure in 1989-90. The minister for higher education, Robert Jackson, announced that $£ 1,680$ million will be distributed to the universities in the next academic year, an increase of 6 per cent from 1988-89, but much of the increase included in the government figures is accounted for by costs for restructuring and agreed pay awards for previous years. The universities' vice-chancellors say the 3 per cent increase is too small, and have asked for an increase of 5 per cent. Jackson also said the universities should plan for an increase in 1990-91 of 4 per cent in cash terms and increases of 3 per cent in the following two years.

C. MCG.

\section{Chip complex destroyed} New Delhi

INDIA's microelectronics industry has been shaken by a fire that almost totally destroyed the $\$ 100$-million semiconductor complex in Chandigarh, the country's only facility for producing silicon chips for civilian needs. Sabotage has not been ruled out as the cause of the fire, which burnt down the entire complex, leaving only some design documents and the administration block. $\mathrm{Mr}$ Virendra Mohan, chief of the facility, has resigned after acknowledging moral responsibility for the accident. There are now fears that many of the nearly 200 engineers working at the Chandigarh complex and who are now out of work may migrate to the West.

India's semiconductor needs will now have to be met by imports or by setting up a new facility that will not be ready before 1992 . 